\title{
An improved route to osmium(IV) tetraaryl complexes
}

\author{
Joseph M. Parr, Ralf Haiges, and Michael S. Inkpen* \\ Department of Chemistry, University of Southern California, Los Angeles, California 90089, \\ United States
}

Email: inkpen@usc.edu

\begin{abstract}
Air-stable, redox-active osmium(IV) tetraaryl complexes can be prepared in yields $\leq 76 \%$ from the novel precursor $\left(\mathrm{Oct}_{4} \mathrm{~N}\right)_{2}\left[\mathrm{OsBr}_{6}\right]$, facilitating the synthesis of $\mathrm{Os}$ (mesityl $)_{4}$ for the first time. This complex exhibits a distorted tetrahedral geometry and three reversible redox events including a $1+/ 2+$ feature not previously observed in this family of materials.
\end{abstract}


Homoleptic transition metal(IV) tetraaryl complexes, M(aryl)4, are an underexplored class of organometallic materials with distinct electrochemical, magnetic, and optical properties resulting from their tetrahedral coordination geometry. ${ }^{1} \mathrm{Os}(\mathrm{IV})^{2-4}$ and $\mathrm{Ru}(\mathrm{IV})^{3-5}$ compounds with ortho-methylated $\sigma$-aryl ligands are particularly robust (consistent with a stable $\mathrm{d}^{4}$ low-spin electronic configuration), where the methyl groups provide steric protection from decomposition pathways such as reductive elimination and ortho-hydrogen abstraction. ${ }^{3}$ They can be purified using chromatography in air, and their aryl ligands can be chemically functionalized via different methods (including bromination, ${ }^{6}$ Suzuki coupling, ${ }^{6}$ and Friedel-Crafts acylation ${ }^{7}$ ). The osmium compounds have a particularly rich redox chemistry which facilitated the early isolation of a stable paramagnetic Os(V) complex. ${ }^{8}$ However, Os(aryl) $)_{4}$ complexes are often obtained in poor yields (typically $\leq 34 \%$, see SI, Table S2) from reactions of aryl Grignard reagents with $\mathrm{OsO}_{4}$ (aryl = 2-tolyl, 2,5-xylyl, 2,4-xylyl, 4-fluoro-2-tolyl, and phenyl). Given the high toxicity of $\mathrm{OsO}_{4}$, and additional purification complications caused by the presence of monooxo(tetraaryl)osmium(VI) ${ }^{9}$ and bisoxo(diaryl)osmium(VI) ${ }^{9,10}$ side products (Figure 1, top), the development of new, high-yielding preparative approaches using alternative starting reagents is desirable.

In this work we report an improved synthetic route to osmium(IV) tetraaryl complexes starting from novel tetra- $n$-octylammonium hexahaloosmate(IV) precursors $\left(\left(\mathrm{Oct}_{4} \mathrm{~N}\right)_{2}\left[\mathrm{OsX}_{6}\right] ; \mathrm{X}=\mathrm{Cl}, \mathrm{Br}\right.$; Figure 1, bottom); our approach can also be used to prepare ruthenium homologues from tetra- $n$-octylammonium hexachlororuthenate(IV). Reactions of the appropriate aryl Grignard reagent with $\left(\mathrm{Oct}_{4} \mathrm{~N}\right)_{2}\left[\mathrm{OsBr}_{6}\right]$ provide $\mathrm{Os}(2-$ tolyl $)_{4}(\text { Os1) and Os(2,5-xylyl })_{4}($ Os2 $)$ in the highest yields reported for any M(aryl $)_{4}$ compound prepared to date $(\geq 75 \%)$. Analogous reactions using mesitylmagnesium bromide provide Os(mesityl) 4 (Os3) in $\leq 21 \%$, a previously inaccessible complex comprising sterically demanding and electron rich 2,6-dimethyl substituted aryl ligands. We unambiguously determine the structure of Os2 and Os3 via single-crystal X-ray diffraction (Figure 2) and explore the redox properties of Os1-3 using solution electrochemistry (Figure 3). 


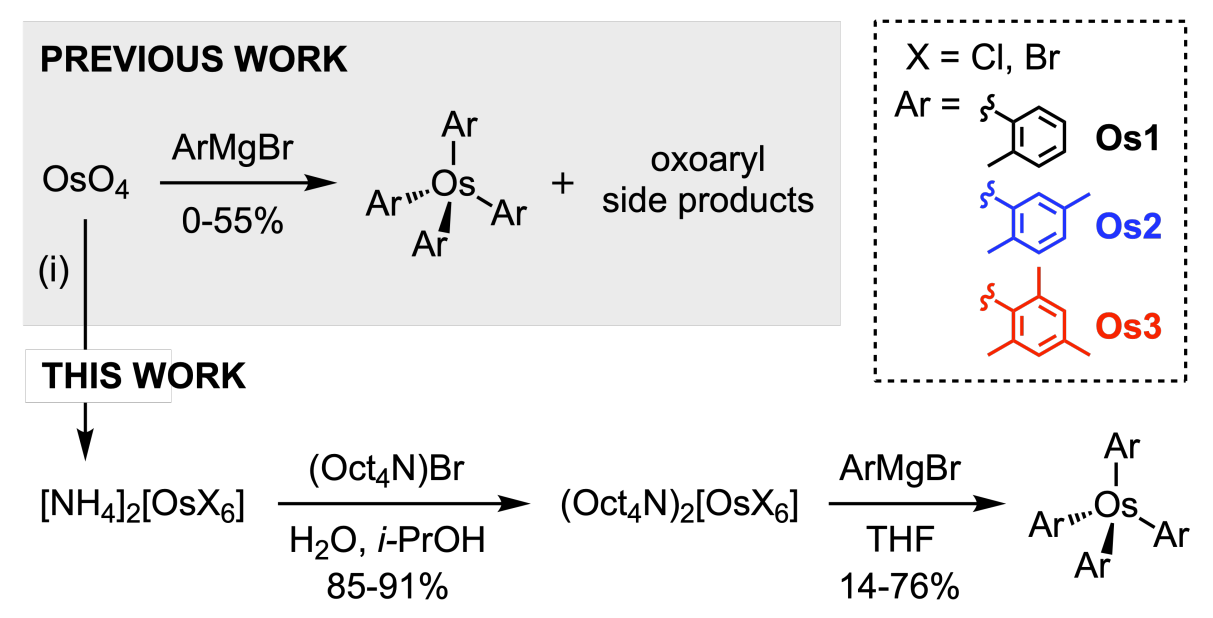

Figure 1. Synthetic routes to Os(aryl $)_{4}$ complexes from reactions of aryl Grignard reagents with $\mathrm{OsO}_{4}$ (previous work, top) or $\left(\mathrm{Oct}_{4} \mathrm{~N}\right)_{2}\left[\mathrm{OsX}_{6}\right]$ (this work, bottom). Conditions: (i) HX, $\mathrm{NH}_{4} \mathrm{X}(\mathrm{X}=\mathrm{Cl}, \mathrm{Br})$, ethanol (and $\mathrm{FeCl}_{2}$ for $\left.\mathrm{X}=\mathrm{Cl}\right) \cdot{ }^{11,12}$ Use of $\left(\mathrm{Oct}_{4} \mathrm{~N}\right)_{2}\left[\mathrm{OsX}_{6}\right]$ avoids the formation of osmium(VI) oxoaryl side products, provides higher yields of Os(aryl $)_{4}$, and facilitates the formation of Os(mesityl $)_{4}(\mathbf{O s} 3)$ for the first time.
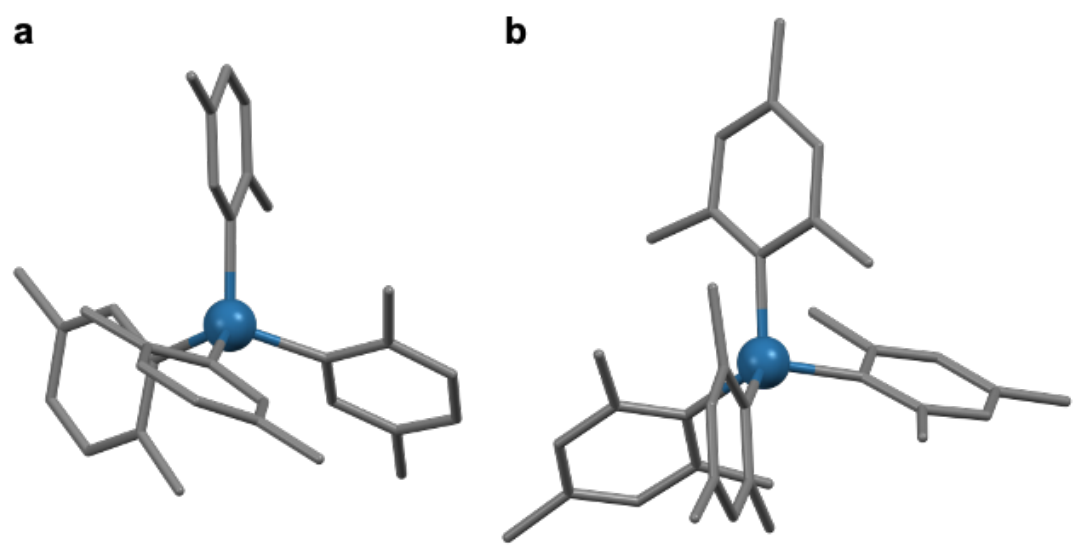

Figure 2. X-ray crystal structures of (a) Os2 and (b) Os3. Hydrogen atoms are omitted for clarity (Os = teal, $\mathrm{C}=$ grey). Selected structural parameters are provided in Table $\mathbf{1}$ and in the SI, Table S7, S8, and S13.

In developing this method, we considered approaches that might reduce or eliminate the formation of osmium(VI) oxoaryl side products. These are reported to originate from the incomplete substitution of $\mathrm{OsO}_{4}$ rather than through air oxidation in solution or during chromatographic purification. ${ }^{9}$ We reasoned that oxoaryl side products could be avoided simply by using alternative oxygen-free osmium precursors, and looked for inspiration from the materials used to prepare analogous ruthenium(IV) tetraaryl complexes. These include $\left(\mathrm{Et}_{4} \mathrm{~N}\right)\left[\mathrm{RuCl}_{5}(\mathrm{THF})\right],{ }^{4}$ $\left(\mathrm{Et}_{4} \mathrm{~N}\right)\left[\mathrm{RuCl}_{5}(\mathrm{MeCN})\right],{ }^{4} \mathrm{Ru}_{2}\left(\mu-\mathrm{O}_{2} \mathrm{CMe}\right)_{4},{ }^{4} \mathrm{RuCl}_{3}(\text { tht })_{3},{ }^{5}$ and $\mathrm{Ru}(\mathrm{acac})_{3}{ }^{13,14}$ (tht = tetrahydrothiophene, acac $=$ acetylacetonate). Unfortunately, yields of the Ru(aryl $)_{4}$ 
products are also low, and methods involving some of these precursors are reportedly difficult to reproduce (SI, Table S1). ${ }^{4,5}$ Given that the use of multinuclear, Ru(II), or $\mathrm{Ru}(\mathrm{III})$ species also have the potential to increase the complexity of reactions, ${ }^{4}$ and noting that the mononuclear pentachlororuthenate salts have not been utilized since the first synthetic reports of $\mathrm{Ru}(\operatorname{aryl})_{4}$ species, we sought alternative easily accessible $\mathrm{M}(\mathrm{IV})$ compounds. Remarkably, several members of the family of $\left(\mathrm{NH}_{4}\right)_{2}\left[\mathrm{MX}_{6}\right]$ salts $(\mathrm{M}=\mathrm{Os}$, $\mathrm{Ru} ; \mathrm{X}=\mathrm{Cl}, \mathrm{Br}$ ) are commercially available or readily synthesized using verified protocols, ${ }^{11,12}$ but have not yet been explored as precursors to $\mathrm{M}(\operatorname{aryl})_{4}$ compounds.

Our initial attempts to prepare $\mathrm{Ru}(2 \text {-tolyl) })_{4}(\mathbf{R u 1})$ by the addition of 6-8 equivalents of 2-tolylmagnesium bromide to $\left(\mathrm{NH}_{4}\right)_{2}\left[\mathrm{RuCl}_{6}\right]$ proved unsuccessful due to the low solubility of the metal salt in THF and diethyl ether (coordinating solvents commonly used for Grignard reactions). However, following cation exchange to increase solubility of the anion in common organic solvents, the analogous reaction using $\left(\mathrm{Oct}_{4} \mathrm{~N}\right)_{2}\left[\mathrm{RuCl}_{6}\right]^{15}$ provided Ru1 in 35\% yield (SI, Figure S1). This yield is comparable to those from previously reported routes (SI, Table S1). We readily adapted this cation exchange protocol to prepare the novel Os(IV) starting materials $\left(\mathrm{Oct}_{4} \mathrm{~N}\right)_{2}\left[\mathrm{OsCl}_{6}\right]$ and $\left(\mathrm{Oct}_{4} \mathrm{~N}\right)_{2}\left[\mathrm{OsBr}_{6}\right]$ in $85 \%$ and $91 \%$ yield, respectively (Figure 1, bottom). Os1 ( $\mathrm{X}=\mathrm{Cl}, 30 \% ; \mathrm{X}=\mathrm{Br}, 75 \%)$ and Os2 ( $\mathrm{X}=\mathrm{Cl}, 44 \% ; \mathrm{X}=\mathrm{Br}, 76 \%)$ could be isolated in high yields following reactions between these salts and the appropriate arylmagnesium bromide (see SI, Table S2 for a summary of previous work). Further demonstrating the advantage of this approach, reaction of mesitylmagnesium bromide with $\left(\mathrm{Oct}_{4} \mathrm{~N}\right)_{2}\left[\mathrm{OsX}_{6}\right]$ provided the novel Os3 complex as a green-black solid $(\mathrm{X}=\mathrm{Cl}$, $14 \% ; \mathrm{X}=\mathrm{Br}, 21 \%$ ). Previous attempts by others to prepare Os(aryl) 4 complexes with bulky 2,6-disubstituted aryl ligands from $\mathrm{OsO}_{4}$, such as $\mathbf{O s 3}$ or Os(2,6-xylyl) only in the formation of $\mathrm{OsO}_{2}(\operatorname{aryl})_{2}$ complexes. ${ }^{3,10,16} \mathbf{O s \mathbf { 1 - 3 }}$ and $\mathbf{R u 1}$ were worked up in air and purified by chromatography without any signs of decomposition.

The solid-state structures of Os 2 and Os3 were determined by single-crystal Xray diffraction and compared to analogous tetrahedral compounds (Figure 2, Table 1 and SI, Tables S7-S20). While M-C bond lengths (Os2 $=2.008(4) \AA$, Os3 $=2.037(3)$ $\AA)$ appear to increase for Os(IV) compounds as the aryl ligands become more electrondonating (phenyl $<2$-tolyl $<2,5$-xylyl $<$ cyclohexyl $<$ mesityl; Table 1 ), the same trend is not observed for the $\mathrm{Ru}(\mathrm{IV})$ analogues. The range of angles between aryl planes does not appear to correlate with the number of ortho-substituents or the electronic character of the aryl ligand (Table 1 and SI, Table S7; see SI, Figure S2 for structural parameter 
definitions). However, we note that Os2 has the largest difference between minimum and maximum aryl plane angles for all compounds surveyed here $\left(36.77^{\circ}\right.$; Table 1$)$.

Table 1. Selected average and calculated structural parameters for different compounds.

\begin{tabular}{|c|c|c|c|c|c|}
\hline compound & $\mathrm{M}-\mathrm{C}(\AA)$ & aryl plane range $\left(^{\circ}\right)$ & $\begin{array}{l}T \text {-value } \\
c\end{array}$ & identifier $^{d}$ & reference \\
\hline Os(mesityl) $)_{4}(\mathbf{O s 3})$ & $2.037(3)$ & 18.96 & 8.02 & 2024176 & this work \\
\hline Os(cyclohexyl $)_{4}$ & 2.029 & - & 5.18 & 1135690 & 3 \\
\hline Os(2-tolyl) $)_{4}($ Os1) & 1.997 & 7.51 & 4.38 & 1135692 & 3 \\
\hline Os(4-Br-2,5-xylyl $)_{4}$ & $2.000(2)$ & 24.87 & 1.60 & 164949 & 6 \\
\hline Os(phenyl) $)_{4}$ & 1.995 & 24.40 & 1.32 & 1153940 & 3 \\
\hline $\mathrm{Os}(2,5-\mathrm{xylyl})_{4}($ Os2 $)$ & $2.008(4)$ & 36.77 & 1.11 & 2024175 & this work \\
\hline $\operatorname{Ru}(\text { mesityl })_{4}(\mathbf{R u 3})$ & 2.01(1) & 17.22 & 7.42 & 1191069 & 5 \\
\hline $\mathrm{Ru}(\text { cyclohexyl })_{4}$ & 2.019 & - & 4.02 & 1153943 & 3 \\
\hline $\mathrm{Ru}(2 \text {-tolyl })_{4}(\mathbf{R u} \mathbf{1})$ & 1.995 & 12.53 & 3.53 & 1161553 & 4 \\
\hline $\mathrm{Ru}(4-\mathrm{MeO}-2 \text {-tolyl })_{4}$ & 1.986 & 26.19 & 2.45 & 1032104 & 13 \\
\hline $\mathrm{Ru}(4-\mathrm{Br}-2,5 \text {-xylyl })_{4}$ & 1.984 & 24.97 & 2.17 & 1032108 & 13 \\
\hline $\begin{array}{l}\operatorname{Ru}(2,4,5- \\
\text { trimethylphenyl })_{4}\end{array}$ & $1.985(10)$ & 20.99 & 0.86 & 1510576 & 14 \\
\hline $\mathrm{C}(\text { phenyl })_{4}$ & 1.551 & 5.98 & 1.95 & 191149 & 17 \\
\hline
\end{tabular}

a Average bond length, provided with pooled estimated standard deviations (ESDs) in parentheses for all structures with associated ESDs. $\mathrm{M}=\mathrm{Os}, \mathrm{Ru}, \mathrm{C} .{ }^{b}$ Difference between minimum and maximum aryl plane angles. ${ }^{c} T$-value (tetrahedricity) $=$ a measure of the mean absolute deviation of a set of $\mathrm{C}-\mathrm{M}-\mathrm{C}$ angles from their ideal tetrahedral values $\left(109.5^{\circ}\right) . T$ value $=0$ indicates no deviation. Calculated using Equation S1. ${ }^{d}$ CCDC Deposition Number.

To simplify comparisons of C-M-C angles we employ a "tetrahedricity"-value ( $T$ value), the root-mean-square deviation of a set of $\mathrm{C}-\mathrm{M}-\mathrm{C}$ angles from their ideal tetrahedral values $\left(109.5^{\circ}\right)$. This is calculated for Os1-3, Ru1, and related compounds using Equation S1, where a $T$-value $=0$ indicates no deviation. An analogous "octahedricity" metric has been utilized in the structural characterization of metal polypyridyl complexes, ${ }^{18-20}$ and related analyses have been performed for coordination environments in solid-state materials. ${ }^{21,22} \mathrm{We}$ observe that $T$-values decrease in the order M3 $>\mathrm{M}(\text { cyclohexyl })_{4}>\mathbf{M 1}$ for both series of Os and Ru compounds (Table 1), suggesting that a greater tetrahedral distortion is required to accommodate aryl ligands of increased steric bulk. This analysis supports the view that steric constraints due to 2,6-dimethyl substituents contribute to the lower synthetic yields of Os3 compared to Os2 and Os1 (SI, Table S2), given that the four mesityl groups of Os3 are arranged in 
a particularly distorted tetrahedral geometry ( $T$-value $=8.02, \mathrm{C}-\mathrm{Os}-\mathrm{C}$ angles between 98.4-117.2 ${ }^{\circ}$. In contrast, complexes with 2,5-xylyl ligands adopt a more ideal tetrahedral structure compared to M1 and materials with simple phenyl substituents (Table 1). For example, Os2 ( $T$-value $=1.11, \mathrm{C}-\mathrm{Os}-\mathrm{C}$ angles between 108.6-110.9 $\left.{ }^{\circ}\right)$ is more tetrahedral than Os1 $(T$-value $=4.38)$, Os $(\text { phenyl })_{4}(T$-value $=1.32)$, or $\mathrm{C}(\text { phenyl })_{4}$ $(T$-value $=1.95)$. In the SI, Figure S3, we present space-filling models that show the 2,6-dimethyl substituents of Os3 provide additional steric shielding around the Os center compared with Os1 and Os2. We hypothesize that 2,6-substituted aryl ligands may impart an increased chemical or electrochemical stability to such complexes, which have been shown to undergo rapid reactions with different Lewis bases. ${ }^{23}$

We studied the redox properties of Os1-3 using cyclic voltammetry in $\mathrm{CH}_{2} \mathrm{Cl}_{2}$ with $0.1 \mathrm{M} \mathrm{NBu}_{4} \mathrm{PF}_{6}$ as the supporting electrolyte. The results are summarized in Table 2 and Table S21, with representative overlaid cyclic voltammograms shown in Figure 3. Voltammograms for Os3 at different scan rates are shown in SI, Figure S4. Os1-3 exhibit two reversible, one-electron transfers $\left(i_{\mathrm{pa}} / i_{\mathrm{pc}} \approx 1, i_{\mathrm{p}} \propto V_{\mathrm{s}}^{1 / 2}\right)$, in broad agreement with previous reports. ${ }^{8,9}$ These $0 / 1+$ and $1-/ 0$ events have previously been assigned to the $\mathrm{Os}^{4+} / \mathrm{Os}^{5+}$ and $\mathrm{Os}^{3+} / \mathrm{Os}^{4+}$ redox couples, respectively. We observe an additional $1+/ 2+$ oxidation event for $\mathbf{O s} 3$ at $+1.117 \mathrm{~V}$ which may be metal $\mathrm{Os}^{5+} / \mathrm{Os}^{6+}$ or ligandbased. Using the equilibrium potentials for the $0 / 1+$ feature of Os1-3, we find that Os(aryl) 4 complexes are approximately $\sim 22 \mathrm{mV}$ easier to oxidize for every methyl substituent added. This is compared to $\sim 50 \mathrm{mV} /$ methyl group for ferrocene analogues. ${ }^{24}$ Using these values, we estimate the $0 / 1+$ equilibrium potential of Os(2,3,4,5,6pentamethylphenyl $)_{4}(\mathbf{O s 5})$ to be around $-0.02 \mathrm{mV}$ vs. $\left[\mathrm{Cp}_{2} \mathrm{Fe}\right]^{+} /\left[\mathrm{Cp}_{2} \mathrm{Fe}\right]$, with a total range of $\sim 350 \mathrm{mV}$ between the mono-substituted and permethylated complexes (4-20 methyl substituents). This compares to $\sim 500 \mathrm{mV}$ between ferrocene and decamethylferrocene (0-10 methyl substituents). 
Table 2. Selected electrochemical data for Os(aryl $)_{4}$ complexes. $^{a}$

\begin{tabular}{|c|c|c|c|c|c|c|c|}
\hline \multirow[t]{2}{*}{ entry } & \multirow[t]{2}{*}{ compound } & \multirow[t]{2}{*}{ solvent } & \multicolumn{4}{|c|}{$E_{1 / 2}(\mathrm{~V})$} & \multirow[t]{2}{*}{ reference } \\
\hline & & & $2-/ 1-$ & $1-/ 0$ & $0 / 1+$ & $1+/ 2+$ & \\
\hline $1^{b}$ & Os(2-tolyl) $)_{4}($ Os1) & THF & -2.47 & -1.89 & +0.41 & - & 8 \\
\hline $2^{b}$ & & $\mathrm{CH}_{2} \mathrm{Cl}_{2}$ & - & -1.96 & +0.33 & - & 8 \\
\hline 3 & & $\mathrm{CH}_{2} \mathrm{Cl}_{2}$ & - & -1.961 & +0.326 & - & this work \\
\hline $4^{c}$ & Os(2,5-xylyl $)_{4}($ Os2 $)$ & $\mathrm{CH}_{2} \mathrm{Cl}_{2}$ & - & $-1.48^{d}$ & +0.24 & - & 9 \\
\hline 5 & & $\mathrm{CH}_{2} \mathrm{Cl}_{2}$ & - & -2.008 & +0.244 & - & this work \\
\hline 6 & Os(mesityl) $)_{4}(\mathbf{O s 3})$ & $\mathrm{CH}_{2} \mathrm{Cl}_{2}$ & - & -2.028 & +0.153 & +1.117 & this work \\
\hline
\end{tabular}

${ }^{a}$ Scan rate $=0.1 \mathrm{~V} \mathrm{~s}^{-1} ; \mathrm{NBu}_{4} \mathrm{PF}_{6}$ supporting electrolyte; working electrode: glassy carbon; reference electrode, counter electrode: Pt. Potentials measured with internal $\mathrm{Cp}^{*}{ }_{2} \mathrm{Fe}(-0.532 \mathrm{~V}$ vs $\left.\left[\mathrm{Cp}_{2} \mathrm{Fe}\right]^{+} /\left[\mathrm{Cp}_{2} \mathrm{Fe}\right]\right),{ }^{24}$ reported relative to $\left[\mathrm{Cp}_{2} \mathrm{Fe}\right]^{+} /\left[\mathrm{Cp}_{2} \mathrm{Fe}\right]$. See SI, Table S22 for additional electrochemical data. ${ }^{b}$ Scan rate $=0.05 \mathrm{~V} \mathrm{~s}^{-1}$; working electrode: Pt; reference electrode: $\mathrm{Ag}$; counter electrode: W. Potentials measured with internal $\mathrm{Cp}_{2} \mathrm{Fe} .{ }^{c}$ Reference electrode: $\mathrm{Ag} / \mathrm{AgNO}_{3}$ (0.1 $\mathrm{M}$ in acetonitrile). Potentials measured with internal $\mathrm{Cp}_{2} \mathrm{Fe} .{ }^{d}$ The reported potential of the 1-/0 redox event is significantly shifted compared to other measurements for these compounds.

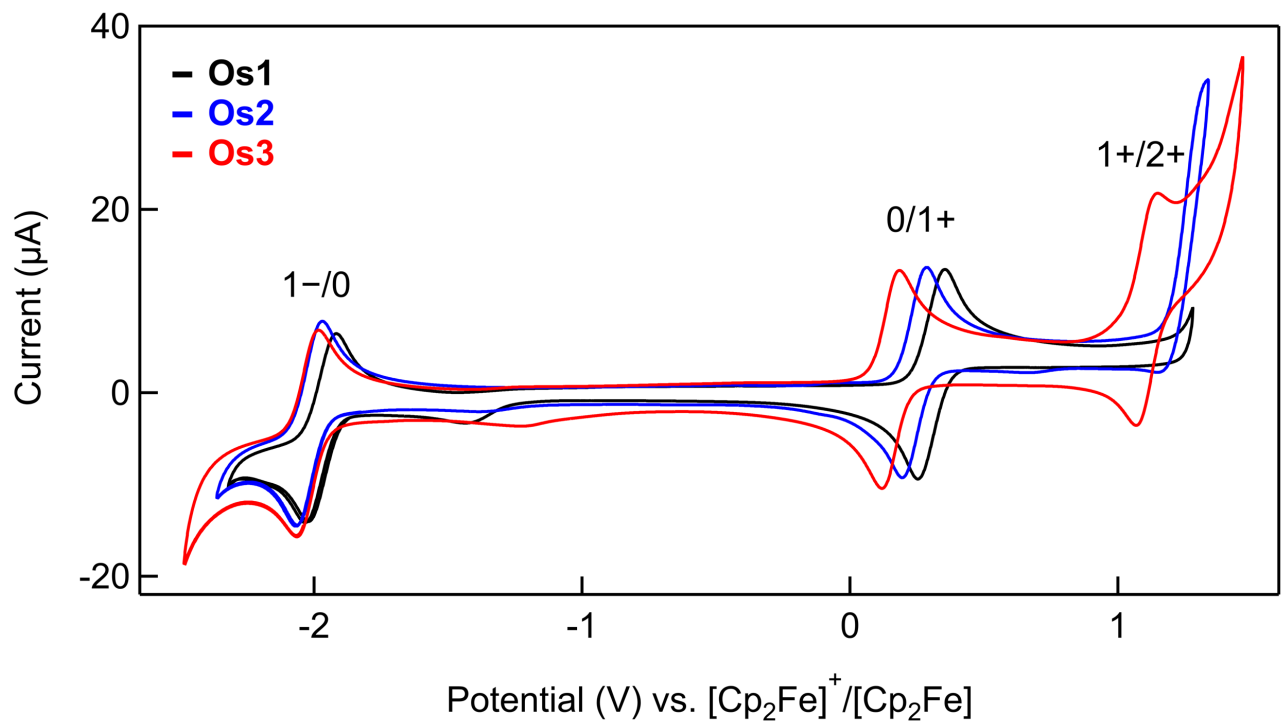

Figure 3. Overlaid cyclic voltammograms for Os(2-tolyl) ${ }_{4}$ (Os1, black), Os(2,5-xylyl) ${ }_{4}$ (Os2, blue), and $\mathrm{Os}(\text { mesityl })_{4}\left(\mathbf{O s 3}\right.$, red) in $0.1 \mathrm{M} \mathrm{NBu}_{4} \mathrm{PF}_{6}-\mathrm{CH}_{2} \mathrm{Cl}_{2}$. Potentials are reported relative to $\mathrm{FcH} /[\mathrm{FcH}]^{+}$, corrected for $i R_{\mathrm{u}}$. Scan rate $=0.1 \mathrm{~V} \mathrm{~s}^{-1}$. Redox features are shifted to cathodic potentials with increasing numbers of methyl substituents, and a second oxidation event is observed for Os3.

\section{CONCLUSION}

In conclusion, we have shown that synthetic yields of Os(aryl) 4 complexes can be significantly improved using the novel starting material $\left(\mathrm{Oct}_{4} \mathrm{~N}\right)_{2}\left[\mathrm{OsBr}_{6}\right]$, even 
facilitating the preparation of previously inaccessible compounds such as Os3. $\left(\mathrm{Oct}_{4} \mathrm{~N}\right)_{2}\left[\mathrm{OsBr}_{6}\right]$ is relatively non-hazardous, straightforward to prepare, and convenient to handle, avoiding the direct use of volatile and toxic $\mathrm{OsO}_{4}$ in reactions with aryl Grignard reagents. By quantifying the degree of tetrahedral distortion in these materials using a tetrahedricity metric, we show how their geometry is altered by varying the degree of substitution at the aryl ligands. Solution electrochemical studies of Os1-3 suggest that the redox potentials of such compounds, with 20 possible substituent positions, can be precisely and systematically tuned. It is hoped that this study will help increase the utility of this fascinating family of complexes in established and emerging areas of molecular materials science.

\section{ASSOCIATED CONTENT}

Electronic Supplementary Information (ESI) available: Experimental procedures, characterization data $\left({ }^{1} \mathrm{H}\right.$ and ${ }^{13} \mathrm{C}\left\{{ }^{1} \mathrm{H}\right\}$ NMR, high-resolution mass spectrometry or elemental analysis) for all new compounds, X-ray crystal structure data for Os 2 and Os3, and solution electrochemical data for Os1-3. CCDC 2024175, 2024176.

\section{AUTHOR INFORMATION}

\section{Corresponding Author}

Michael S. Inkpen - Email: inkpen@usc.edu

\section{Notes}

The authors declare no competing interests.

\section{ACKNOWLEDGEMENTS}

This work was supported by University of Southern California (USC) startup funds. J.M.P. is grateful for support from a USC Wrigley Institute for Environmental Studies Norma and Jerol Sonosky Environmental Sustainability Graduate Summer Fellowship. The authors thank John Arnold (University of California, Berkeley) for valuable discussions.

\section{REFERENCES}

1. Koschmieder, S. U. \& Wilkinson, G. Homoleptic and related aryls of transition metals. Polyhedron 10, 135-173 (1991).

2. Tooze, R. P., Stavropoulos, P., Motevalli, M., Hursthouse, M. B. \& Wilkinson, G. 
Synthesis and x-ray crystal structures of the first tetrahedral osmium(IV) compounds, tetrakis(cyclohexyl)osmium(IV) and tetrakis(o-methylphenyl)osmium(IV). J. Chem. Soc. Chem. Commun. 0, 1139-1140 (1985).

3. Stavropoulos, P., Savage, P. D., Tooze, R. P., Wilkinson, G., Hussain, B., Motevalli, M. \& Hursthouse, M. B. The synthesis and X-ray crystal structures of homoleptic tetrahedral aryls of osmium(IV) and of cyclohexyls of ruthenium(IV), osmium(IV), and chromium(IV). J. Chem. Soc. Dalt. Trans. 557-562 (1987).

4. Savage, P. D., Wilkinson, G., Motevalli, M. \& Hursthouse, M. B. Synthesis of homoleptic tetrahedral aryls of rhenium(IV) and ruthenium(IV). X-Ray crystal structures of tetrakis(o-methylphenyl)rhenium(IV), tetrakis(omethylphenyl)oxorhenium(VI), and tetrakis(o-methylphenyl)-ruthenium(IV). J. Chem. Soc., Dalt. Trans. 669-673 (1988) doi:10.1039/dt9880000669.

5. Hay-Motherwell, R., Wilkinson, G., Hussain-Bates, B. \& Hurthouse, M. Homoleptic Mesityls of 1ridium(lw/,v) and Ruthenium(lv,v). Dalton Trans. 3477-3482 (1992).

6. Lau, M. K., Zhang, Q. F., Chim, J. L. C., Wong, W. T. \& Leung, W. H. Direct functionalisation of $\sigma$-aryl ligands: Preparation of homoleptic functionalised aryls of osmium(IV). Chem. Commun. 1, 1478-1479 (2001).

7. Savage, P. D. Organometallic Compounds of Rhenium and the Platinum Group Metals. (Ph.D. thesis, Imperial College of Science \& Technology, 1987).

8. Arnold, J., Wilkinson, G., Hussain, B. \& Hursthouse, M. B. Redox chemistry of the homoleptic aryl Os(2-MeC6H4)4: synthesis and characterization of the first osmium(V) organometallic [Os(2-MeC6H4)4][CF3SO3]. J. Chem. Soc. Chem. Commun. 1349-1350 (1988) doi:10.1039/c39880001349.

9. Lau, M.-K., Chim, J. L., Wong, W.-T., Williams, I. D. \& Leung, W.-H. Synthesis and molecular structures of monooxo aryl complexes of osmium(VI). Can. J. Chem. 79, 607-612 (2001).

10. Stravropoulos, P., Edwards, P. G., Behling, T., Wilkinson, G., Motevalli, M. \& Hursthouse, M. B. Oxoaryls of rhenium-(V) and -(VI) and osmium(VI). X-Ray crystal structures of dimesityldioxorhenium(VI), tetramesityloxorhenium(VI), and dimesityldioxoosmium(VI). J. Chem. Soc. Dalt. Trans. 169-175 (1987) doi:10.1039/DT9870000169.

11. Dwyer, F. P., Hogarth, J. W. \& Rhoda, R. N. Ammonium Hexachloroosmate (IV). Inorg. Synth. 5, 206-207 (1957).

12. Dwyer, F. P., Hogarth, J. W. \& Rhoda, R. N. Ammonium Hexabromoosmate (IV). 
Inorg. Synth. 5, 204-206 (1957).

13. So, S. C., Cheung, W. M., Wang, G. C., Kwan Huang, E., Lau, M. K., Zhang, Q. F., Sung, H. H. Y., Williams, I. D. \& Leung, W. H. Migratory insertion and reductive coupling of tetraarylruthenium(IV) complexes. Organometallics 33, 4497-4502 (2014).

14. Wang, C.-J., Wu, X.-L., Ma, X.-F., Jia, A.-Q. \& Zhang, Q.-F. Synthesis and crystal structure of a new homoleptic tetraarylruthenium(IV) complex Ru(2,4,5-Me3C6H2)4. Z. Naturforsch 72, 523-525 (2017).

15. Rodriguez, J. R., Félix, R. M., Reynoso, E. A., Fuentes Moyado, S. \& Alonso-Núñez, G. Coordination complex synthesis of noble metals in the preparation of nanoparticles supported on MWCNTs used as electrocatalysts. Inorganica Chim. Acta 406, 138-145 (2013).

16. Longley, C. J., Savage, P. D., Wilkinson, G., Hussain, B. \& Hurthouse, M. Alkylimido and oxo aryls of rhenium. X-ray structures of (BuittN)2ReCl2(o-MeC6H4) and MO2(2,6-Me2C6H3)2, M = Re and Os. Polyhedron 7, 1079-88 (1988).

17. Knop, O., Rankin, K. N., Cameron, T. S. \& Boyd, R. J. Crystal chemistry of tetraradial species. Part 10. Tilting at windmills: Conformations of the tetraphenyl species $\mathrm{ZPh} 40$, $\pm 1(\mathrm{Z}=\mathrm{B}, \mathrm{C}, \mathrm{N}) 1$. Can. J. Chem. 80, 1351-1366 (2002).

18. Brown, C. M., Arsenault, N. E., Cross, T. N. K., Hean, D., Xu, Z. \& Wolf, M. O. Structural, electrochemical and photophysical behavior of $\mathrm{Ru}(\mathrm{ii})$ complexes with large bite angle sulfur-bridged terpyridyl ligands. Inorg. Chem. Front. 7, 117-127 (2020).

19. Österman, T., Abrahamsson, M., Becker, H.-C., Hammarström, L. \& Persson, P. Influence of Triplet State Multidimensionality on Excited State Lifetimes of Bistridentate RuII Complexes: A Computational Study. J. Phys. Chem. A 116, 1041-1050 (2012)

20. Lundqvist, M. J. Quantum Chemical Modeling of Dye-Sensitized Titanium Dioxide : Ruthenium Polypyridyl and Perylene Dyes, TiO2 Nanoparticles, and Their Interfaces. (Ph.D. thesis, Uppsala University, 2006).

21. Hiwatari, Y., Saito, T. \& Ueda, A. Structural characterization of soft-core and hardcore glasses by Delaunay tessellation. J. Chem. Phys. 81, 6044-6050 (1984).

22. Medvedev, N. N. \& Naberukhin, Y. I. Shape of the delaunay simplices in dense random packings of hard and soft spheres. J. Non. Cryst. Solids 94, 402-406 (1987).

23. Arnold, J., Wilkinson, G., Hussain, B. \& Hursthouse, M. B. Reactivity of the homoleptic osmium aryl Os(2-MeC6H4)4: ligand-induced reductive coupling, .sigma.- 
to .pi.-rearrangement, and ortho-hydrogen activation. Organometallics 8, 1362-1369 (1989).

24. Noviandri, I., Brown, K. N., Fleming, D. S., Gulyas, P. T., Lay, P. A., Masters, A. F. \& Phillips, L. The Decamethylferrocenium/Decamethylferrocene Redox Couple: A Superior Redox Standard to the Ferrocenium/Ferrocene Redox Couple for Studying Solvent Effects on the Thermodynamics of Electron Transfer. J. Phys. Chem. B 103, 6713-6722 (1999). 